\title{
Correction to: Wideband Antipodal Vivaldi Antenna Using Metamaterial for Micrometer and Millimeter Wave Applications
}

\section{Sumit Kumar ${ }^{1} \cdot$ Amruta S. Dixit $^{1}$}

Published online: 5 November 2021

(c) Springer Science+Business Media, LLC, part of Springer Nature 2021

\section{Correction to: Journal of Infrared, Millimeter, and Terahertz Waves https://doi.org/10.1007/s10762-021-00799-2}

The original article has been corrected. "Fig. $2 \mathrm{a}$ " was missing.

Sumit Kumar and Amruta S. Dixit are first author and second author, respectively.

The original article can be found online at https://doi.org/10.1007/s10762-021-00799-2.

\section{Sumit Kumar}

er.sumitkumar21@gmail.com

1 Symbiosis International (Deemed University), Symbiosis Institute of Technology, Pune, India 


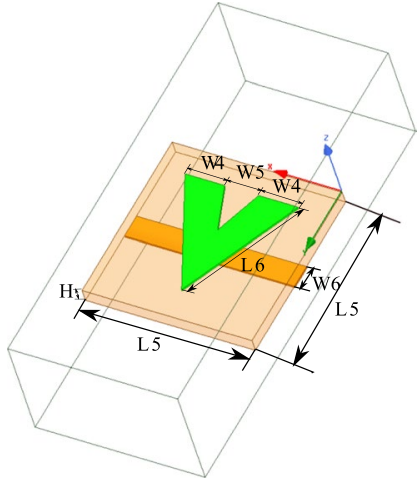

(a)

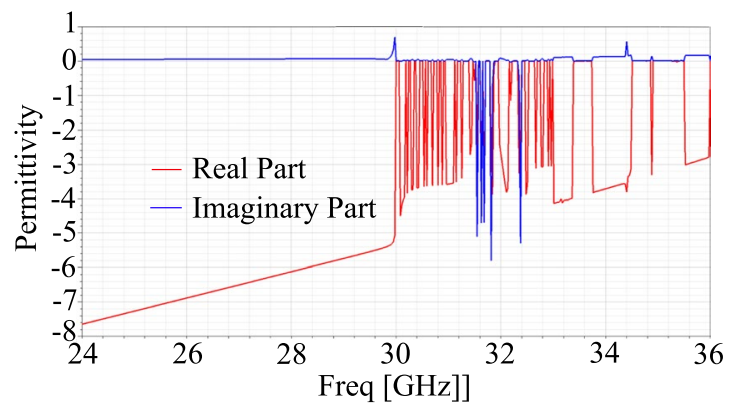

Fig. 2 Design of MUC. a MUC design. b Relative permittivity of the MUC

Publisher's Note Springer Nature remains neutral with regard to jurisdictional claims in published maps and institutional affiliations. 